\author{
NICK ALLEN, PT, MSc ${ }^{1,2,3}$ • ALAN NEVILL, PhD² • JOHN BROOKS, PhD ${ }^{4}$ \\ YIANNIS KOUTEDAKIS, PhD2,5,6 • MATTHEW WYON, PhD'1,2,3
}

\title{
Ballet Injuries: Injury Incidence and Severity Over 1 Year
}

B allet dancers are described as both artists and athletes, ${ }^{19,25}$ performing complex artistic routines that require a high level of athletic ability due to the extreme physical demands placed on them. ${ }^{51}$ Consequently, ballet dancers are at risk for injuries that can potentially disrupt performance and curtail a career. ${ }^{23,51}$ The van Mechelen et $a^{56}$ injury prevention model indicates the need to understand the extent of the injury problem. However, within dance,

this has been challenging due to methodological deficiencies and inconsistencies in published epidemiological studies. ${ }^{4,22,27}$ These include the choice of research design, such as injury surveys ${ }^{3,26,28,46}$ and retrospective data collection, ${ }^{17,37}$ and variations in injury definitions, including medical attention ${ }^{17,37}$ and financial cost. ${ }^{18}$ When examined prospectively, the incidence of dance injury has been reported to be between 0.62 and 5.6 injuries per

STUDY DESIGN: Prospective, descriptive single-cohort study.

OBJECTIVE: To assess the incidence and severity of injuries to a professional ballet company over 1 year.

METHODS: Data for an elite-level ballet company of 52 professional dancers were collected by an in-house medical team using a time-loss injury definition.

RESULTS: A total of 355 injuries were recorded, with an overall injury incidence of 4.4 injuries per 1000 hours (female, 4.1; male, 4.8; $P>.05$ ) and a mean of 6.8 injuries per dancer (female, 6.3 ; male, $7.3 ; P>.05)$. Mean injury severity was 7 days

1000 dancing hours..$^{19,30,38}$ Two of these studies were based on preprofessional dancers, ${ }^{19,30}$ which may render the findings less generalizable to a professional ballet company. ${ }^{22,53}$

Although epidemiological studies can aid in the understanding of the injury profile, allowing appropriate interventions to reduce the risk of injury, ${ }^{34,35,40}$ the epidemiology of injuries in ballet is not well understood. Therefore, the pur-

(female, 4; male, 9; $P<.05)$. Most injuries were classified as overuse (64\%; female, $68 \%$; male, $60 \% ; P>.05)$; mean severity of injury was 3 days for females and 9 days for males $(P<.05)$. The percentage of traumatic injuries was $32 \%$ for females and $40 \%$ for males $(P<.05)$; the corresponding severity was 6 and 10 days, respectively $(P<.05)$.

CONCLUSION: The relatively high number of injuries reported and the resulting loss of dance time support the need to introduce interventions to reduce the risk of injury in professional dancers. J Orthop Sports Phys Ther 2012;42(9):781-790. Epub 19 July 2012. doi:10.2519/jospt.2012.3893

KEY WORDS: dance, overuse, traumatic pose of this study was to undertake injury surveillance of professional ballet dancers to enhance our understanding of injuries and to provide a foundation for future interventions to reduce injury incidence. Specific objectives were to report the incidence, severity, and etiology of injuries sustained by a cohort of professional ballet dancers, including the nature of the injuries as intrinsic or extrinsic, whether they were traumatic or from overuse, and the episode of injury (first occurrence, exacerbation, or recurrence). Furthermore, the objective was to look at the impact of dance activity and the dancers' rank on injuries and whether differences occur between genders.

\section{METHODS}

A PROFESSIONAL BALLET COMPANY composed of 52 dancers (female, 27 ; male, 25) was prospectively studied over 1 performance year. Female dancers had a mean \pm SD age of $25 \pm 6$ years, height of $162.2 \pm 3.7 \mathrm{~cm}$, weight of $49.2 \pm 4.0 \mathrm{~kg}$, and body mass index of $18.9 \pm 1.6 \mathrm{~kg} / \mathrm{m}^{2}$. Male dancers had a mean \pm SD age of $23 \pm 5$ years, height of $179.6 \pm 4.3 \mathrm{~cm}$, weight of $71.7 \pm 4.7$ $\mathrm{kg}$, and body mass index of $22.2 \pm 1.4 \mathrm{~kg} /$ $\mathrm{m}^{2}$. All dancers were assigned a rank for the entire year based on their position in the company. The highest rank within the company is principal, followed by soloist,

${ }^{1}$ Clinical Director, Birmingham Royal Ballet Company, The Jerwood Centre, Birmingham Royal Ballet, Birmingham, UK. 2Professor, Research Centre for Sport Exercise and Performance, University of Wolverhampton, Walsall, UK. ${ }^{3}$ National Institute of Dance Medicine and Science, London, UK. ${ }^{4}$ Injury Analyst, Rugby Football Union, Twickenham, UK. ${ }^{5}$ Professor, Department of Sport Science, Thessaly University, Thessaly, Greece. ${ }^{6}$ Institute of Human Performance and Rehabilitation, Trikala, Greece. The protocol of this study was approved by the University of Wolverhampton Ethics Committee. The opinions or assertions contained herein are the private views of the authors and are not to be construed as official or as reflecting the views of any of the affiliated organizations. Address correspondence to Nick Allen, The Jerwood Centre, Birmingham Royal Ballet, Thorp Street, Birmingham B5 4AU, UK. E-mail: nickallen@brb.org.uk • Copyright @2012 Journal of Orthopaedic \& Sports Physical Therapy 


\begin{tabular}{|c|c|c|c|}
\hline \multirow[t]{2}{*}{ TABLE 1} & \multicolumn{3}{|c|}{ INCIDENCE AND SEVERITY OF INJURIES } \\
\hline & Female & Male & Total \\
\hline Injuries, $\mathrm{n}$ & 172 & 183 & 355 \\
\hline Exposure, $\mathrm{h}$ & 41499 & 38425 & 79924 \\
\hline Incidence, $\mathrm{n}^{*}$ & $4.14(3.57,4.81)$ & $4.76(4.12,5.51)$ & $4.44(4.00,4.93)$ \\
\hline Severity, $\mathrm{d}^{+}$ & $4(4,5)$ & $9(8,11)^{\ddagger}$ & $7(6,8)$ \\
\hline Absence, $d^{\S}$ & $16.6(14.4,19.5)$ & $44.7(38.7,51.7)$ & $30.2(27.2,33.5)$ \\
\hline \multicolumn{4}{|c|}{$\begin{array}{l}\text { *Values are the number of injuries per } 1000 \text { hours of dance (95\% confidence interval). } \\
{ }^{*} \text { Values are the mean number of days lost due to the injury ( } 95 \% \text { confidence interval). } \\
{ }^{*} \text { Denotes statistical significance }(P<.05) \text { compared to severity in females. } \\
\text { \$Values are the total number of days lost per } 1000 \text { hours of dance (95\% confidence interval). }\end{array}$} \\
\hline
\end{tabular}

\begin{tabular}{|c|c|c|c|c|}
\hline \multirow[t]{3}{*}{ TABLE 2} & \multicolumn{4}{|c|}{$\begin{array}{l}\text { Incidence ANd Severity of Injuries } \\
\text { By Nature, Episode, ANd Activities }\end{array}$} \\
\hline & \multicolumn{2}{|c|}{ Female } & \multicolumn{2}{|c|}{ Male } \\
\hline & Incidence* & Severity ${ }^{\dagger}$ & Incidence* & Severity ${ }^{\dagger}$ \\
\hline \multicolumn{5}{|l|}{ Nature } \\
\hline Extrinsic & $1.49(1.16,1.92)$ & $3(3,4)$ & $1.64(1.28,2.10)$ & $5(4,7)$ \\
\hline Intrinsic & $2.65(2.20,3.20)$ & $4(4,5)$ & $3.12(2.61,3.73)$ & $12(10,14)$ \\
\hline \multicolumn{5}{|l|}{ Episode } \\
\hline First episode & $2.05(1.66,2.53)$ & $5(4,6)$ & $0.49(0.32,0.78)$ & $59(38,93)$ \\
\hline Exacerbation & $0.46(0.29,0.72)$ & $4(3,6)$ & $2.76(2.28,3.34)$ & $2(2,3)$ \\
\hline Recurrence & $1.64(1.29,2.08)$ & $3(3,4)$ & $1.51(1.17,1.95)$ & $7(5,8)$ \\
\hline \multicolumn{5}{|l|}{ Activity } \\
\hline Class & $4.94(3.70,6.59)$ & $4(3,5)$ & $7.54(5.91,9.61)$ & $13(11,17)$ \\
\hline Rehearsal & $2.43(1.88,3.14)$ & $2(2,3)$ & $2.99(2.35,3.80)$ & $4(3,5)$ \\
\hline Performance & $4.45(3.22,6.14)$ & $7(5,10)$ & $5.19(3.81,7.08)$ & $13(9,17)$ \\
\hline
\end{tabular}

with first artist and artist constituting the corps de ballet. Female principals had a mean \pm SD age of $28 \pm 4$ years, soloists an age of $29 \pm 4$ years, first artists an age of $23 \pm 2$ years, and artists an age of 21 \pm 3 years. Male principals had a mean \pm SD age of $28 \pm 3$ years, soloists an age of $27 \pm 4$ years, first artists an age of $24 \pm 4$ years, and artists an age of $20 \pm 2$ years. The different ranks largely determined the different dancing demands. All dancers were injury free at the beginning of the study. The dancers had access to free in-house medical care, which included 3 physiotherapists, 2 masseurs, and 1 body conditioner.

The company's workload was repre- sented in 2 distinct periods: a rehearsal period, which entailed class and rehearsals that took place 6 days a week over blocks of 2 to 6 weeks, followed by a performance period. During the performance period, class and rehearsals still took place (although rehearsal times were reduced). The company performed in blocks of 2 to 6 weeks, averaging 7 performances per week. Dancers performed in 145 performances of 15 different shows over the study period. While resident at the home theater, the company's class and rehearsals took place in its own dance studios, which had sprung floors. Dancers rehearsed in a combination of ballet flats/slippers, pointe (female), and char-

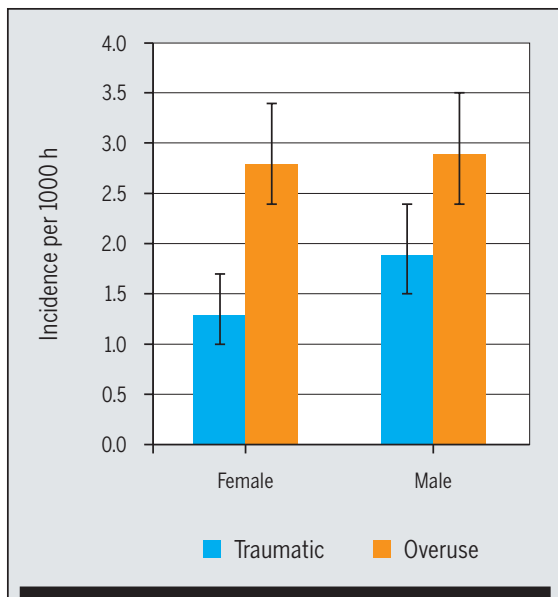

FIGURE 1. The incidence of traumatic and overuse injuries by gender.

acter shoes (during rehearsals and performances). While on tour, the company's class and rehearsals generally took place in visiting studios or on theater stages with varying degrees of sprung floors. Half of the company's performances took place in its home theater and half on tour. The company did not have a consistent touring surface. A medical team attended tours. The dancers had a 1-week midseason break and a 5 -week break over the summer; therefore, they danced 20 performance weeks and 26 rehearsal weeks, for a total of 46 weeks in 1 year. The average number of dance hours per week during rehearsal periods was 31.5 hours, while dancers averaged 35.5 hours during performance periods. The study was approved by the University of Wolverhampton Ethics Committee.

\section{Injury Reporting}

Injuries were reported using a time-loss definition of injury, as modified from Brooks et al, ${ }^{8,9}$ whereby data were collected for "any injury that prevented a dancer from taking a full part in all dance-related activities that would normally be required of them for a period equal to or greater than 24 hours after the injury was sustained." ${ }^{\prime, 9}$ Injuries were reported by 1 of the 3 full-time, inhouse physiotherapists on a standardized injury-assessment form (ONLINE APPENDIX). Injury severity was defined by the num- 


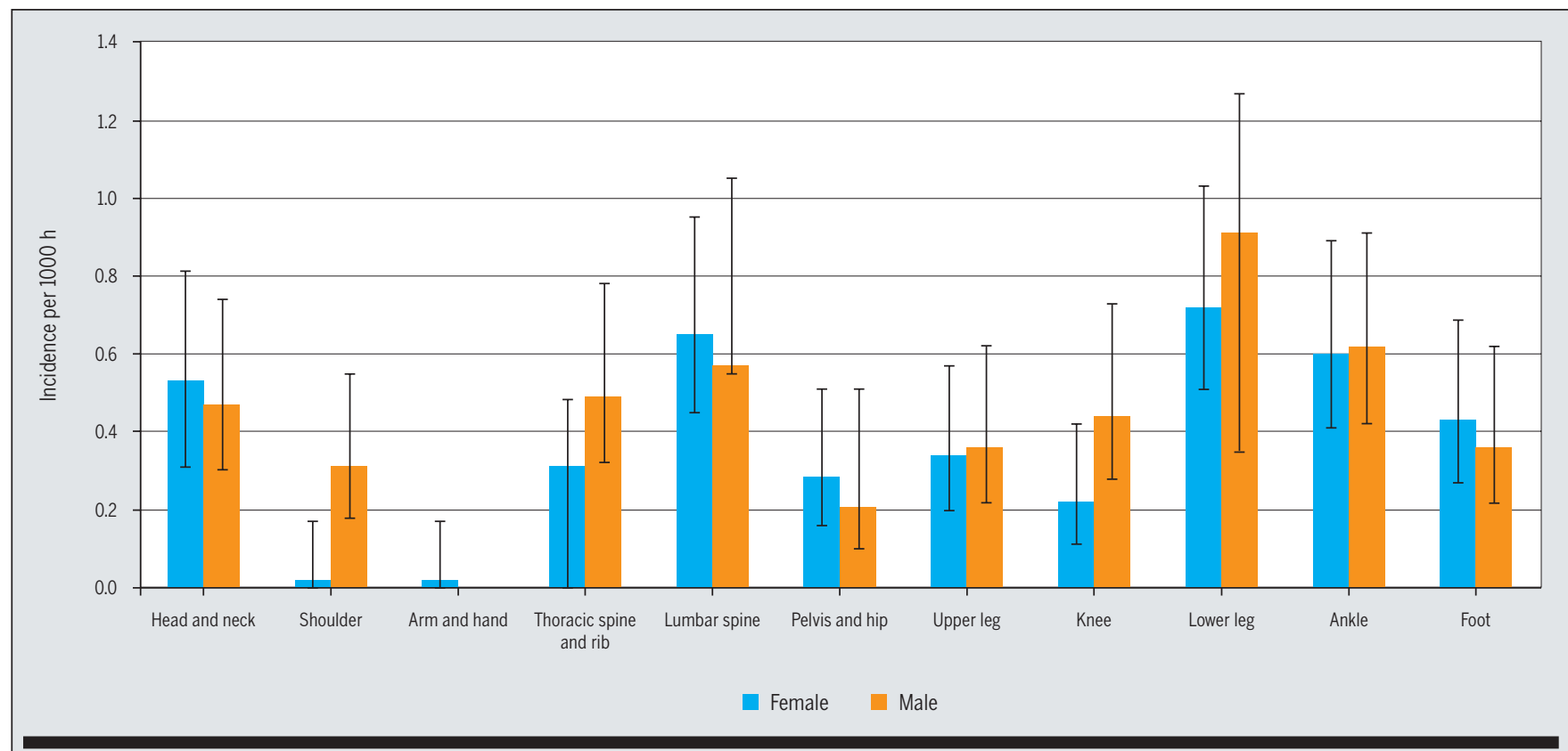

FIGURE 2. Incidence and injured body region for male and female dancers.

ber of days a dancer took to return to full fitness, and full fitness was defined as the ability to take a full part in the dance activities that were typically planned for that day. This definition was modified from studies by Brooks et al, ${ }^{8,9}$ Fuller et $\mathrm{al}^{177,18}$ and Pluim et al. ${ }^{44}$ Injury severity was grouped as transient (return within 7 days), mild (return within 7 to 28 days), moderate (return within 29 to 84 days), and severe (return after 84 , days). ${ }^{8,9,20}$ Reported injury history was used to determine the mechanism of injury.

Injury diagnosis was recorded using Version 9 of the Orchard Sports Injury Classification System. ${ }^{41}$ During analysis, the injuries and body regions were grouped into areas of clinical interest, while providing sufficient numbers for meaningful analysis. A recurrent injury was defined as an injury of the same type and at the same site as the index (firstepisode) injury, occurring after a dancer's return to full participation from the index injury within 2 months (definitions modified from Fuller et $\mathrm{al}^{16}$ ). An exacerbation was defined as a worsening of the state of a nonrecovered complaint, such that the dancer could not take a full part in dancerelated activities that would normally be required (definitions modified from Fuller et $\mathrm{al}^{16}$ ). All other injuries were classified as first-episode injuries. Injuries were either classified as traumatic (an injury that resulted from a specific identifiable event) or overuse (an injury caused by repeated microtrauma without a single identifiable event responsible for the injury). ${ }^{17}$ The nature of the cause of injury was classified as either intrinsic (injuries related to the characteristics of an individual participant [eg, strength and joint stability]) or extrinsic (injuries arising from external sources [eg, surfaces, protective equipment, and props]) (ONLINE APPENDIX). ${ }^{3,33,56}$ Dancing exposure was recorded and calculated by the lead researcher, using detailed call sheets and performance schedules that contractually dictated the daily activities of dancers within the company. Exposure was calculated using data for all dancers within the company.

\section{Data Analysis}

The severity of injuries was calculated as the number of days between the date of injury and the date of return to dancing, and reported as mean severity, with $95 \%$ confidence intervals (CIs). ${ }^{57}$ The incidence of injury and total days of ab- sence due to injuries were calculated as the number of injuries or number of days absent per 1000 hours of dancing, with 95\% CIs. ${ }^{58}$ A Poisson distribution model was used to calculate CIs. ${ }^{8,9,20}$ A significant difference between categories or groups was assumed if the $95 \%$ CIs did not overlap. ${ }^{42}$ A Pearson correlation was applied to individually calculated injury incidences and individual injury numbers to determine whether there might be an association between age and injury. All correlations and associations were calculated using Minitab Version 16 software (Minitab Inc, State College, PA).

\section{RESULTS}

A LTHOUGH ALL DANCERS IN THE company recorded at least 1 injury during the study, 2 of the dancers incurred their injury outside of the dance-related exposure period (class, rehearsal, and performances) and were not included in the analysis. Therefore, data are reported for 50 of the 52 dancers.

During the 1-year period, a mean of 6.8 injuries per dancer (females, 6.3; males, $7.3 ; P>.05)$ were recorded. The mean severity of injury was significantly 


\begin{tabular}{|c|c|c|c|c|}
\hline Injury Grouping & Injuries* & Incidence $^{\dagger}$ & Mean Severity ${ }^{\ddagger}$ & Absence $^{\S}$ \\
\hline Cervical facet joint dysfunction/nerve root pathology & $14(8)$ & $0.34(0.20,0.57)$ & $4(2,6)$ & $1(0.70,1.99)$ \\
\hline Neck muscle spasm/strain/tear & $7(4)$ & $0.17(0.08,0.35)$ & $3(1,6)$ & $0(0.23,1.01)$ \\
\hline Shoulder muscle/joint spasm/strain/tear/sprain & $1(1)$ & $0.02(0.00,0.17)$ & $2(0,14)$ & $0(0.01,0.34)$ \\
\hline Other head/neck/arm pathology & $1(1)$ & $0.02(0.00,0.17)$ & $2(0,14)$ & $0(0.01,0.34)$ \\
\hline Thoracic facet joint/rib dysfunction & $5(3)$ & $0.12(0.05,0.29)$ & $9(4,21)$ & $1(0.44,2.55)$ \\
\hline Thoracic muscle spasm/strain/tear & $8(5)$ & $0.19(0.10,0.39)$ & $3(1,5)$ & $1(0.25,1.01)$ \\
\hline Lumbar muscle spasm/strain/tear & $11(6)$ & $0.27(0.15,0.48)$ & $2(1,4)$ & $1(0.35,1.13)$ \\
\hline Lumbar pain undiagnosed & $3(2)$ & $0.07(0.02,0.22)$ & $6(2,18)$ & $0(0.13,1.27)$ \\
\hline Gluteal/hip (including psoas) muscle spasm/strain/tear & $8(5)$ & $0.19(0.10,0.39)$ & $3(1,5)$ & $1(0.25,1.01)$ \\
\hline Thigh muscle spasm/strain/tear & $20(12)$ & $0.48(0.31,0.75)$ & $4(3,6)$ & $2(0.91,3.99)$ \\
\hline Knee joint/ligament derangement & $8(5)$ & $0.19(0.10,0.39)$ & $5(2,9)$ & $1(0.33,2.31)$ \\
\hline Calf muscle spasm/strain/tear & $7(4)$ & $0.17(0.08,0.35)$ & $4(2,8)$ & $1(0.32,1.42)$ \\
\hline Lower-leg pain undiagnosed & $10(5)$ & $0.24(0.13,0.45)$ & $3(2,6)$ & $1(0.39,1.34)$ \\
\hline Achilles tendinopathy & $0(0)$ & $\ldots$ & $\ldots$ & $\ldots$ \\
\hline Ankle instability/ligament sprain, including sinus tarsi & $11(7)$ & $0.27(0.15,0.48)$ & $6(3,11)$ & $2(0.92,3.00)$ \\
\hline Ankle impingement/jarring/joint capsule sprain & $2(1)$ & $0.05(0.01,0.19)$ & $3(1,14)$ & $0(0.04,0.67)$ \\
\hline Ankle pain undiagnosed & $5(3)$ & $0.12(0.05,0.29)$ & $2(1,5)$ & $0(0.10,0.58)$ \\
\hline Foot muscle spasm/strain/tear & $9(5)$ & $0.22(0.11,0.42)$ & $6(3,12)$ & $1(0.68,2.50)$ \\
\hline Sprain foot/toe joint & $0(0)$ & $\ldots$ & $\ldots$ & $\ldots$ \\
\hline First metatarsophalangeal joint pain & $6(3)$ & $0.14(0.06,0.32)$ & $5(2,12)$ & $1(0.34,1.66)$ \\
\hline All injuries & $172(100)$ & $4.14(3.57,4.81)$ & $4(3,5)$ & $17(14.42,19.45)$ \\
\hline
\end{tabular}

*Values are $n$ (percent of all injuries).

${ }^{+}$Values are the number of injuries per 1000 hours of dance (95\% confidence interval).

${ }^{\ddagger}$ Values are the mean number of days lost due to the injury (95\% confidence interval).

${ }^{\S}$ Values are the total number of days lost per 1000 hours of dance (95\% confidence interval).

higher $(P<.05)$ in male dancers $(9$ days $)$ than in female dancers (4 days) (TABLE 1$)$. The majority of injuries in female dancers were classified as transient $(94 \%)$, and the remaining injuries were classified as mild (5\%) or moderate ( $1 \%)$. There were no severe injuries in female dancers. Similarly, the majority of injuries in male dancers were classified as transient ( $87 \%$ ), and the remaining injuries were classified as mild ( $9 \%)$, moderate $(2 \%)$, or severe $(2 \%)$.

In both male and female dancers, the number of injuries classified as transient was significantly greater $(P<.05)$ than the number of injuries classified as mild, moderate, or severe.

\section{Mechanism of Injury}

A large number of the mechanisms of injury were classified as "cannot recall" (19.6\%) or "other" (25.8\%). Otherwise, the largest proportion of injuries were sustained during jumping activities, with small, middle, and large jumps accounting for $9.9 \%, 5.9 \%$, and $9.0 \%$ of all injuries, respectively. Performing arabesque accounted for $7.1 \%$ of dance injuries, whereas lifting accounted for $5.9 \%$ and pointe work accounted for another $5.2 \%$.

\section{Intrinsic and Extrinsic Factors}

Data on the nature of the injuries indicated a similar incidence of injuries due to extrinsic factors in females (1.49/1000 h) and males (1.64/1000 h). However, there was a greater incidence of injuries related to intrinsic factors for males $(3.12 / 1000 \mathrm{~h})$ compared to females $(2.65 / 1000 \mathrm{~h})$. Injuries related to intrinsic factors accounted for the majority of injuries (female, 64\%; male, 66\%), as well as the greatest percentage of days absent (female, 70\%; male, 80\%) (TABLE 2). The incidence and severity of injuries related to intrinsic factors were greater than those of injuries related to extrinsic factors $(P<.05)$.

\section{Overuse/Traumatic Injuries}

Overuse accounted for $68 \%$ of injuries in females and $60 \%$ of injuries in males 


\begin{tabular}{|c|c|c|c|c|}
\hline Injury Grouping & Injuries* & Incidence $^{\dagger}$ & Mean Severity ${ }^{\ddagger}$ & Absence ${ }^{\S}$ \\
\hline Cervical facet joint dysfunction/nerve root pathology & $11(6)$ & $0.29(0.16,0.52)$ & $5(3,9)$ & $1(0.79,2.58)$ \\
\hline Neck muscle spasm/strain/tear & $6(3)$ & $0.16(0.07,0.35)$ & $4(2,10)$ & $1(0.32,1.56)$ \\
\hline Other head/neck/arm pathology & $9(5)$ & $0.05(0.01,0.21)$ & $3(1,12)$ & $1(0.33,5.31)$ \\
\hline Thoracic facet joint/rib dysfunction & $13(7)$ & $0.34(0.20,0.58)$ & $4(2,6)$ & $1(0.74,2.20)$ \\
\hline Thoracic muscle spasm/strain/tear & $5(3)$ & $0.13(0.05,0.31)$ & $3(1,7)$ & $0(0.16,0.94)$ \\
\hline Lumbar muscle spasm/strain/tear & $13(7)$ & $0.34(0.20,0.58)$ & $6(4,11)$ & $2(1.27,3.76)$ \\
\hline Lumbar pain undiagnosed & $3(2)$ & $0.08(0.03,0.24)$ & $2(1,6)$ & $0(0.05,0.48)$ \\
\hline Gluteal/hip (including psoas) muscle spasm/strain/tear & $5(3)$ & $0.13(0.05,0.24)$ & $3(1,8)$ & $0(0.18,1.06)$ \\
\hline Thigh muscle spasm/strain/tear & $19(10)$ & $0.49(0.32,0.78)$ & $4(3,7)$ & $2(1.04,4.58)$ \\
\hline Knee joint/ligament derangement & $16(9)$ & $0.42(0.26,0.68)$ & $11(7,19)$ & $5(2.26,9.93)$ \\
\hline Calf muscle spasm/strain/tear & $15(8)$ & $0.39(0.24,0.65)$ & $4(3,7)$ & $2(1.0,2.76)$ \\
\hline Lower-leg pain undiagnosed & $4(2)$ & $0.10(0.04,0.28)$ & $2(1,6)$ & $0(0.09,0.62)$ \\
\hline Achilles tendinopathy & $1(1)$ & $0.03(0.00,0.18)$ & $13(2,92)$ & $0(0.05,2.40)$ \\
\hline Ankle instability/ligament sprain, including sinus tarsi & $11(6)$ & $0.29(0.16,0.52)$ & $13(7,24)$ & $4(2.12,6.91)$ \\
\hline Ankle impingement/jarring/joint capsule sprain & $6(3)$ & $0.16(0.07,0.35)$ & $7(3,16)$ & $1(0.49,2.43)$ \\
\hline Ankle pain undiagnosed & $3(2)$ & $0.08(0.03,0.24)$ & $2(1,7)$ & $0(0.06,0.56)$ \\
\hline Foot muscle spasm/strain/tear & $7(4)$ & $0.18(0.09,0.38)$ & $3(1,6)$ & $1(0.26,1.15)$ \\
\hline Sprain foot/toe joint & $3(2)$ & $0.08(0.03,0.24)$ & $18(6,57)$ & $1(0.46,4.44)$ \\
\hline First metatarsophalangeal joint pain & $3(2)$ & $0.08(0.03,0.24)$ & $3(1,9)$ & $0(0.08,0.73)$ \\
\hline All injuries & $183(100)$ & $4.76(4.12,5.51)$ & $9(8,11)$ & $45(38.68,51.68)$ \\
\hline
\end{tabular}

*Values are $n$ (percent of all injuries).

${ }^{\top}$ Values are the number of injuries per 1000 hours of dance (95\% confidence interval).

${ }^{\ddagger}$ Values are the mean number of days lost due to the injury (95\% confidence interval).

${ }^{\$}$ Values are the total number of days lost per 1000 hours of dance (95\% confidence interval).

(FIGURE 1), resulting in $54 \%$ and $58 \%$ of time lost for females and males, respectively. Overuse injuries were statistically greater in incidence and severity than traumatic injuries $(P<.05)$ in both female and male dancers.

\section{Episode}

Female dancers experienced a significantly $(P<.05)$ higher incidence of first-episode injuries (49\%) than male dancers, and reported fewer recurrences $(40 \%)$ and exacerbations $(11 \%)(P<.05)$. First episodes also represented a higher proportion of time lost (TABLE 2). Male dancers recorded a significantly $(P<.05)$ higher incidence of exacerbations. First- episode injuries accounted for a significantly higher amount of time lost $(P<.05)$ in male dancers (TABLE 2).

\section{Body and Injury Grouping}

The majority of injuries sustained were to the lower leg, ankle, and lumbar regions (FIGURE 2). Thigh muscle spasms/strains/ tears, ankle instability/ligament sprains, medial tibial stress syndrome, cervical facet joint dysfunction/nerve root pathology, and lumbar muscle spasms/strains/ tears were the most common injuries overall. Females reported a higher incidence of lumbar facet joint dysfunction/ nerve root pathology (TABLE 3), whereas males reported a higher incidence of calf muscle spasms/strains/tears, thoracic facet joint/rib dysfunction, shoulder muscle spasms/strains/tears/sprains, and shoulder subacromial impingement (TABLE 4). The highest percentage of time lost was due to stress fractures of the tibia and metatarsals (male, $35 \%$ ), ankle instability (male, $9 \%$; female, $10 \%$ ), and lumbar facet joint dysfunction/nerve root pathology (female, 9\%).

\section{Activity}

When comparing the 3 dance-related activities (class, rehearsal, and performance), both female and male dancers experienced a significantly lower incidence of injury during rehearsals com- 


\section{RESEARCH REPORT}

pared to incidence during classes and performance $(P<.05)$. Injuries sustained during performances accounted for significantly $(P<.05)$ greater time lost for female dancers $(47 \%)$, with an average severity of 7 days per injury, whereas injuries sustained during rehearsals accounted for significantly less time lost $(P<.05)$ for female and male dancers, with an average severity of 2 and 4 days, respectively. Male dancers recorded the highest percentage of time-loss injuries in class $(53 \%)$, with an average severity of 13 days (TABLE 2).

\section{Rank and Age}

The male principals, first artists, and artists all experienced a significantly higher incidence of injury than the soloists $(P<.05)$, and among female dancers artists experienced the highest incidence of injury, which was significantly higher than that experienced by principals and first artists $(P<.05)$. For the female dancers, the first artists recorded the lowest incidence of injury. The severity of injury was highest in female artists (29 days of absence per dancer) and soloists (28 days of absence per dancer), and in male first artists (125 days of absence per dancer) and principals (121 days of absence per dancer) (TABLE 5). There was no correlation between age and incidence $(r=$ $-0.20, P=.16)$ and age and number of injuries $(r=-0.19, P=.18)$.

\section{DISCUSSION}

$\mathbf{T}$ HE PURPOSE OF THIS STUDY WAS TO report the incidence, severity, and etiology of injuries sustained by a cohort of professional ballet dancers. The injury definition and methodology were consistent with those of other studies of injury incidence in sport ${ }^{8-10}$ and the 3 international consensus statements on injury data collection in sport. ${ }^{17,18,44}$

As $94 \%$ of female dancers' and $87 \%$ of male dancers' injuries in this study resolved in less than 7 days, the 5 -week holiday period that preceded this study provided the opportunity for resolution

\begin{tabular}{|c|c|c|c|c|c|c|}
\hline \multicolumn{2}{|c|}{ TABLE 5} & \multicolumn{5}{|c|}{$\begin{array}{c}\text { INCIDENCE AND SEVERITY OF INJURIES } \\
\text { PER GENDER AND RANK }\end{array}$} \\
\hline \multirow[b]{2}{*}{ Rank } & \multicolumn{3}{|c|}{ Female } & \multicolumn{3}{|c|}{ Male } \\
\hline & Dancers, $\mathbf{n}$ & Incidence* & Severity ${ }^{\dagger}$ & Dancers, $\mathbf{n}$ & Incidence* & Severity ${ }^{\dagger}$ \\
\hline Principal & 4 & $3.25(2.10,5.04)$ & $5(3,7)$ & 4 & $5.20(3.68,7.36)$ & $15(11,21)$ \\
\hline Soloist & 7 & $4.18(3.12,5.60)$ & $4(3,6)$ & 4 & $1.14(0.54,2.39)$ & $2(1,4)$ \\
\hline First artist & 5 & $2.34(1.48,3.72)$ & $5(3,8)$ & 5 & $5.86(4.37,7.84)$ & $14(10,19)$ \\
\hline Artist & 11 & $5.26(4.28,6.48)$ & $4(3,4)$ & 12 & $5.37(4.41,6.54)$ & $6(5,7)$ \\
\hline All dancers & 27 & $4.14(3.57,4.81)$ & $4(3,5)$ & 25 & $4.76(4.12,5.51)$ & $9(8,11)$ \\
\hline
\end{tabular}

of any previous injuries and allowed us to include all dancers within the company at the start of the study. Over the 1-year period of the study, our professional ballet dancers experienced 4.44 injuries per 1000 hours of dance, which represents the upper end of the range of incidence previously reported in prospective epidemiological studies of ballet dancers $(0.62-5.6 / 1000 \mathrm{~h}) .^{19,30,38} \mathrm{~A}$ difference in the levels of participation (preprofessional versus professional) in 2 of the 3 previously published prospective dance studies, ${ }^{19,30}$ coupled with the failure of the third study ${ }^{38}$ to describe the injury definition, precludes their comparability. In regard to other studies of dancerelated injury, the wide variety of injury definitions used and the methodological deficiencies also prevent any meaningful data comparison. For example, a study of a modern dance company reported a much lower incidence of injury, but the differences between modern dance and ballet and the injury definition used, which required a financial outlay, could explain the differences. ${ }^{7}$ The time-loss injury definition used in the current study made it easy to objectively identify and report injuries that directly impacted the dancers' ability to perform dance-related activities. International consensus within sports $^{17,18,44}$ and the National Collegiate Athletic Association Injury Surveillance System $^{12,32}$ have determined that a similar time-loss definition should be utilized in injury epidemiology studies.

Professional ballet dancers perform a high number of dance-related hours per week (a mean of 34 hours per week in the current study), which has resulted in a mean of 6.8 injuries per dancer per year. It would therefore appear prudent to encourage the implementation of injury prevention and therapeutic interventions in an attempt to reduce the impact of these injuries. ${ }^{15,56}$ Improving medical support and a greater focus on injury prevention have been shown to have a positive impact on injury rate in dancers. ${ }^{7,52}$

\section{Mechanism of Injury}

The sports literature has often reported the percentage or incidence of injuries relating to mechanism of injury, ${ }^{1,10,13}$ and the dance literature has often looked to links between specific injuries and mechanism of injury. ${ }^{4,38,46,59}$ In an attempt to understand the causes of dance injuries, data on how an injury occurred were collected, as well as dancers' reports on the mechanism of their injury, selected from a list on the standardized assessment form. Although the majority of injuries were seen within 24 hours of the injury event, a large proportion of dancers could not recall the inciting event, which is consistent with the higher incidence of overuse injuries in that population. A proportion of dancers also felt that the mechanism of injury was not covered by the categories presented on the standardized list and therefore classified the mechanism of injury as "other." The purpose of a standardized list is to provide meaningful groups for analysis; however, 
as this list failed to capture a proportion of the mechanisms of injury, further work is needed to examine what deletions and additions need to be made. In addition, it was also anticipated that an activity like arabesque might not always be the cause of an injury but, rather, exposed a limitation in dancing capacity due to the injury. A higher proportion of injuries related to jumps was anticipated, with the smaller jumps involving increased loading on the lower-leg muscles ${ }^{57}$ and the larger jumps involving greater ground reaction forces, ${ }^{39}$ both of which may increase overall fatigue and risk of injury. ${ }^{61}$

\section{Intrinsic/Extrinsic Factors}

Risk assessment in sport or dance necessitates identifying risk factors that can be categorized as intrinsic or extrinsic. ${ }^{3,15,33,56}$ A number of studies in the dance literature have suggested that both intrinsic and extrinsic factors need to be considered when examining injuries in dance. ${ }^{6,29}$ In the present study, the nature of injuries as intrinsic or extrinsic was determined by the clinician, based on the history of the injury. These categories were further delineated (ONLINE APPENDIX) to assist in decisions regarding injury management of the patient. The nature of the injuries recorded in this study suggests that a greater risk may result from intrinsic causation factors, with both female and male dancers recording a higher rate of injuries sustained intrinsically (2.65/1000 $\mathrm{h}$ and $3.12 / 1000 \mathrm{~h}$, respectively) than extrinsically (1.49/1000 $\mathrm{h}$ and $1.64 / 1000 \mathrm{~h}$, respectively). A potentially important extrinsic factor may arise from the energy return and force reduction properties of the various surfaces (eg, sprung-floor stage) on which the company performs. When considering extrinsic risk, the opportunity to modify a factor such as surface presents a challenge due to the restrictions on resources and access to the various surfaces, and should therefore be considered for future study. A more feasible and applicable approach would be to consider interventional strategies that primarily focus on intrinsic factors, which are more readily modifiable.

\section{Overuse/Traumatic Injuries}

The presence of highly repetitive dance movements in both training and performance is likely the reason for the greater incidence of overuse compared to traumatic injuries in this population (female overuse, $2.82 / 1000 \mathrm{~h}$; female traumatic, 1.49/1000 h; male overuse, 2.84/1000 h; male traumatic, $1.93 / 1000 \mathrm{~h}$ ). This appears consistent with other dance studies that have described a greater percentage of overuse injuries. ${ }^{7,30,38,50-52}$ Traumatic injuries were generally of greater severity in both female (overuse, 3 days; traumatic, 6 days) and male dancers (overuse, 9 days; traumatic, 10 days). It is possible that the free and accessible in-house medical care available at this ballet company facilitated the reporting of overuse injuries at an early stage, prompting early intervention and quicker resolution of the injury. This is in contrast to traumatic injuries, in which damage to anatomical structures may require greater time to heal despite early intervention.

\section{Episode/Recurrence}

It is recognized that a previous injury may increase the risk of sustaining a similar injury in the future. ${ }^{1}$ Because risk assessment and management are part of the objective of injury surveillance, it is important to record the occurrence of each injury episode. Female dancers in this study had 2.05 first-episode injuries, 0.46 exacerbation injuries, and 1.64 recurrent injuries per 1000 hours. Male dancers had 0.49 first-episode injuries, 2.76 exacerbation injuries, and 1.51 recurrent injuries per 1000 hours. The reason for the higher exacerbationinjury rate in male dancers may be linked to the nature of the medical provision at this company and the injury definition used. This company employed 3 full-time in-house physiotherapists, with the advantage that dancers could often attend treatment sessions for musculoskeletal injuries, allowing them to continue a full dance workload. When dancers' symptoms worsened and impacted their ability to perform, these injuries were reported as an exacerbation. This study chose to account for those dancers who were undergoing treatment but were not limited in their performance capacity, as this appeared to be standard practice in this company. As part of an evaluation of patient management in high-performance environments, the use of episode classification provides important information on how the management of patients' activity levels during injury may be evaluated. For example, having established that a high proportion of injuries were recurrent, as this study did, clear returnto-dancing criteria for injured dancers could be defined. The decision to return to full dancing activity is usually reached via consensus between the dancer and the medical team. Understanding the level of recurrence can help steer this process and inform enthusiastic dancers as to the risk of an early return to dancing. It may further add value by allowing an evaluation of the rehabilitation process.

\section{Body Region and Injury Grouping}

This study reported a high proportion of lower-limb injuries, particularly in the lower leg (females, $17 \%$; males, $19 \%$ ), ankle (females, $15 \%$; males, $13 \%$ ), and foot (females, $10 \%$; males, $8 \%$ ), and lumbar injuries (females, 16\%; males, $12 \%)$. This is consistent with a previous report on dancers ${ }^{26}$ and the demands on the lower limbs related to the technical aspects of ballet and the extreme ranges of movement required of the lumbar region. ${ }^{49}$ Those data are also consistent with previously published data on ballet injuries. ${ }^{19,21,31,37,38,45,52,60}$ In the present study, $5 \%$ of injuries in female dancers and $9 \%$ of injuries in male dancers occurred in the knee region, which is similar to the data from 2 of the larger injury surveillance studies reported in the literature. ${ }^{7,52}$ The $13 \%$ and $10 \%$ of injuries in female and male dancers, respectively, recorded for the neck region are consistent with findings in the litera- 
ture,,$^{14,36,37,47,52}$ although the studies that used self-reporting ${ }^{11}$ or seeking medical advice $^{46}$ in their methodology failed to report injuries to the neck region. Perhaps due to these methodologies, dancers failed to perceive the impact of neck injuries to the same extent that they perceived lower extremity and lumbar injuries. The differences observed in injury profile between female and male dancers may be explained by the disparate choreographic demands of classical ballet. The demands and nature of lifting for males may account for the increase in lumbar, thoracic, and shoulder pathologies, whereas the requirement of going en pointe may explain the higher incidence of foot muscle spasms/strains/ tears and first metatarsophalangeal joint pain in female dancers. ${ }^{31,36,45,48,60}$

\section{Activity, Rank, and Age}

The lowest incidence of injury was reported during rehearsal, in which activities tend to be less physically intense and there are frequent breaks for explanations and directions from choreographers. ${ }^{62}$ The highest incidence of injury was reported during class. This is in contrast to the findings of Bronner et $a l,{ }^{7}$ who reported a greater incidence of injury during performances. The intensity and dance-related activity of performance and rehearsal depend on the particular choreography/repertoire, which may contain sessions in which dancers do not need to perform, for example, full jumps or pointe work. Class represents a progression from lowimpact barre work to high-intensity and high-skill "center" work, including large jumps and turns and, for female dancers, en pointe. Considering the consistent exposure to this high-impact, highintensity work in class versus the more occasional exposures during rehearsals or performances, it is expected that with an injury definition based on the ability to undertake all dance activity required, a higher proportion of injuries would be reported during class, as it would be within these sessions that a limitation would be noted.

The dancer's role within a particular choreography is determined largely by rank and gender, factors that also appear to influence the injury rate, despite the similarity of overall incidence of injury in females and males. Male principals performed major roles in which intense periods of solo dance pieces were coupled with supporting and lifting female partners in pas de deux..$^{54}$ The male first artists also performed many roles similar to those of the principals during this study period, and, consequently, both experienced a higher incidence of injury compared with male soloists, who were more commonly character dancers with less strenuous roles. The artists represent the youngest and least experienced members of the company, and they also reported the highest incidence of injury overall. The transition from full-time vocational (dance) school to the corps de ballet in a professional company can provide a number of challenges for these dancers, including the need to develop their technical expertise, as well as to achieve the strength and fitness levels required to perform at the professional level. These demands might have contributed to the increased rate of injury in both male and female dancers in comparison to other ranks. A difference in injury incidence was noted between the genders within the rank of first artist. Unlike a number of male first artists, female first artists were not used in principal roles, thereby reducing the comparative intensity of their workload and subsequently their risk of injury.

The association between age and injury has been found to be inconsistent in the dance literature. ${ }^{7}$ In a study of Broadway performers, a link between higher age and injury was suggested. ${ }^{14}$ Another study reported that dancers older than 25 years of age incurred greater shoulder and foot and ankle injuries. ${ }^{47}$ In contrast, other studies have reported a greater incidence of ankle injuries and stress fractures of the foot in younger dancers ${ }^{38}$ or in the category of 21- to 25-year-olds. ${ }^{51}$ In this study, no correlations were noted between age and injury incidence or injury numbers. This suggests that the demands placed on dancers in this company appear to be a greater predictor of injury than age; as such, considering rank/roles and workload in particular, these demands are an important consideration in injury prevention strategies.

\section{Limitations}

This study has a number of limitations. The reliability and validity of the injury surveillance tool were not established. Due to the decision to implement this tool within a high-performance environment, it was decided that the same datacollection process from a seminal study on injury surveillance in high-performance sport ${ }^{8,9}$ should be used to improve confidence in the outcomes. In addition, a standardized injury data-collection form was developed to replace initialcontact medical records. One perceivable weakness of this method could be the failure of dancers to report injuries that result not in their inability to continue with all activities but in their ability to continue performing in a restricted capacity. Author bias in injury diagnosis may also be perceived as a limitation. International injury diagnosis codes ${ }^{41}$ and weekly injury meetings with medical staff were used to reduce reporting bias. The use of estimated exposure may be a further limitation. Measured individual exposures will enhance our understanding of the challenges of dance and our confidence to provide suitable solutions to injury in the future. Although the company in question has a consistent repertoire and the amount of dance-related activity is determined by the contractual regulations of the dancers' union, along with consistent dancer numbers in the 3 years preceding this study, it should also be acknowledged that the sampling of data over 1 year might have affected the level of precision and that extending the period of study may enhance confidence in the trends observed. 


\section{CONCLUSION}

$\mathbf{P}$ ROFESSIONAL BALLET DANCERS REport a high proportion of lowerlimb, lumbar spine, and overuse injuries. Gender differences in injury incidence and profile were identified that may be explained by the different roles dancers perform. Considering the impact of injury in dance, there is a need to introduce interventions to reduce injury risk.

\section{KEY POINTS}

FINDINGS: Dancers recorded an overall incidence of 4.44 injuries per 1000 hours of dance.

IMPLICATIONS: There is a need to introduce interventions to reduce the risk of injury due to the high number of injuries reported and concomitant loss of valuable dance hours.

CAUTION: This study was undertaken on a sample of professional ballet dancers performing a mixed repertoire that included classical and contemporary ballets. This mixed exposure may limit the comparability of the data to those of other dance cohorts.

\section{REFERENCES}

1. Agel J, Palmieri-Smith RM, Dick R, Wojtys EM, Marshall SW. Descriptive epidemiology of collegiate women's volleyball injuries: National Collegiate Athletic Association Injury Surveillance System, 1988-1989 through 2003-2004. J Athl Train. 2007;42:295-302.

2. Bahr R, Bahr IA. Incidence of acute volleyball injuries: a prospective cohort study of injury mechanisms and risk factors. Scand J Med Sci Sports. 1997;7:166-171.

3. Bahr R, Holme I. Risk factors for sports injuries-a methodological approach. Br J Sports Med. 2003;37:384-392.

4. Bowling A. Injuries to dancers: prevalence, treatment, and perceptions of causes. BMJ. 1989;298:731-734.

5. Brinson P, Dick F. Fit to Dance? The Report of the National Inquiry Into Dancers' Health and Injury. London, UK: Calouste Gulbenkian Foundation; 1996.

6. Bronner S, Ojofeitimi S, Mayers L. Comprehensive surveillance of dance injuries: a proposal for uniform reporting guidelines for professional companies. J Dance Med Sci. 2006;10:69-80.

7. Bronner S, Ojofeitimi S, Rose D. Injuries in a modern dance company: effect of comprehensive management on injury incidence and time loss. Am J Sports Med. 2003;31:365-373.

8. Brooks JH, Fuller CW, Kemp SP, Reddin DB. Epidemiology of injuries in English professional rugby union: part 1 match injuries. Br J Sports Med. 2005;39:757-766. http://dx.doi.org/10.1136/ bjsm.2005.018135

9. Brooks JH, Fuller CW, Kemp SP, Reddin DB. Epidemiology of injuries in English professional rugby union: part 2 training injuries. $\mathrm{Br}$ J Sports Med. 2005;39:767-775. http://dx.doi. org/10.1136/bjsm.2005.018408

10. Brooks JH, Fuller CW, Kemp SP, Reddin DB. A prospective study of injuries and training amongst the England 2003 Rugby World Cup squad. Br J Sports Med. 2005;39:288-293. http://dx.doi.org/10.1136/bjsm.2004.013391

11. Chmelar RD, Fitt SS, Schultz BB, Ruhling RO, Zupan MF. A survey of health, training, and injuries in different levels and styles of dancers. Med Probl Perform Art. 1987;2:61-66.

12. Dick R, Agel J, Marshall SW. National Collegiate Athletic Association Injury Surveillance System commentaries: introduction and methods. J Athl Train. 2009;44:173-182.

13. Dick R, Hootman JM, Agel J, Vela L, Marshall SW, Messina R. Descriptive epidemiology of collegiate women's field hockey injuries: National Collegiate Athletic Association Injury Surveillance System, 1988-1989 through 2002-2003. J Athl Train. 2007;42:211-220.

14. Evans RW, Evans RI, Carvajal S. A survey of injuries among Broadway performers: types of injuries, treatments, and perceptions of performers Med Probl Perform Art. 1996;11:15-19.

15. Fuller $C$, Drawer $S$. The application of risk management in sport. Sports Med. 2004;34:349-356.

16. Fuller CW, Bahr R, Dick RW, Meeuwisse WH. A framework for recording recurrences, reinjuries, and exacerbations in injury surveillance. Clin J Sport Med. 2007;17:197-200. http://dx.doi. org/10.1097/JSM.0b013e3180471b89

17. Fuller CW, Ekstrand J, Junge A, et al. Consensus statement on injury definitions and data collection procedures in studies of football (soccer) injuries. Scand J Med Sci Sports. 2006;16:83-92. http://dx.doi. org/10.1111/j.1600-0838.2006.00528.x

18. Fuller CW, Molloy MG, Bagate $C$, et al. Consensus statement on injury definitions and data collection procedures for studies of injuries in rugby union. Clin J Sport Med. 2007;17:177-181. http:// dx.doi.org/10.1097/JSM.0b013e31803220b3

19. Gamboa JM, Roberts LA, Maring J, Fergus A. Injury patterns in elite preprofessional ballet dancers and the utility of screening programs to identify risk characteristics. J Orthop Sports Phys Ther. 2008;38:126-136. http://dx.doi. org/10.2519/jospt.2008.2390

20. Garraway WM, Lee AJ, Hutton SJ, Russell
EB, Macleod DA. Impact of professionalism on injuries in rugby union. Br J Sports Med. 2000;34:348-351.

21. Garrick JG, Requa RK. Ballet injuries. An analysis of epidemiology and financial outcome. Am J Sports Med. 1993;21:586-590.

22. Hamilton $\mathrm{D}$, Aronsen $\mathrm{P}$, Loken JH, et al. Dance training intensity at 11-14 years is associated with femoral torsion in classical ballet dancers. Br J Sports Med. 2006;40:299-303; discussion 303. http://dx.doi.org/10.1136/ bjsm.2005.020941

23. Hamilton WG, Hamilton LH, Marshall P, Molnar M. A profile of the musculoskeletal characteristics of elite professional ballet dancers. Am J Sports Med. 1992;20:267-273.

24. Hincapie CA, Morton EJ, Cassidy JD. Musculoskeletal injuries and pain in dancers: a systematic review. Arch Phys Med Rehabil. 2008;89:1819-1829. http://dx.doi.org/10.1016/j. apmr.2008.02.020

25. Khan K, Brown J, Way S, et al. Overuse injuries in classical ballet. Sports Med. 1995;19:341-357.

26. Koutedakis Y, Jamurtas A. The dancer as a performing athlete: physiological considerations. Sports Med. 2004;34:651-661.

27. Koutedakis Y, Sharp NCC. The Fit and Healthy Dancer. Chichester, UK: John Wiley \& Sons Ltd; 1999.

28. Laws H, Apps J, Bramley I, Parker D. Fit to Dance 2: Report of the Second National Inquiry Into Dancers' Health and Injury in the UK. London, UK: Dance UK; 2006.

29. Liederbach M, Richardson M. The importance of standardized injury reporting in dance. J Dance Med Sci. 2007;11:45-48.

30. Luke A, Kinney S, D'Hemecourt PA, Baum J, Owen M, Micheli LJ. Determinants of injuries in young dancers. Med Probl Perform Art. 2002;17:105-112.

31. Macintyre J, Joy E. Foot and ankle injuries in dance. Clin Sports Med. 2000;19:351-368.

32. Marshall SW, Covassin T, Dick R, Nassar LG, Agel J. Descriptive epidemiology of collegiate women's gymnastics injuries: National Collegiate Athletic Association Injury Surveillance System, 1988-1989 through 2003-2004. J Athl Train. 2007;42:234-240.

33. Meeuwisse WH. Predictability of sports injuries. What is the epidemiological evidence? Sports Med. 1991;12:8-15.

34. Meeuwisse WH, Love EJ. Athletic injury reporting. Development of universal systems. Sports Med. 1997;24:184-204.

35. Meeuwisse WH, Sellmer R, Hagel BE. Rates and risks of injury during intercollegiate basketball. Am J Sports Med. 2003;31:379-385.

36. Milan KR. Injury in ballet: a review of relevant topics for the physical therapist. J Orthop Sports Phys Ther. 1994;19:121-129.

37. Milan KR. Literature review of common injuries in the performing artist. Orthop Phys Ther Clin North Am. 1996;5:421-453.

38. Nilsson C, Leanderson J, Wykman A, Strender 
LE. The injury panorama in a Swedish professional ballet company. Knee Surg Sports Traumatol Arthrosc. 2001;9:242-246.

39. Norcross MF, Blackburn JT, Goerger BM, Padua DA. The association between lower extremity energy absorption and biomechanical factors related to anterior cruciate ligament injury. Clin Biomech (Bristol, Avon). 2010;25:1031-1036. http://dx.doi.org/10.1016/j. clinbiomech.2010.07.013

40. Orchard J, Newman D, Stretch R, Frost W, Mansingh A, Leipus A. Methods for injury surveillance in international cricket. J Sci Med Sport. 2005;8:1-14.

41. OSICS: The Orchard Sports Injury Classification System. Available at: http://www.sportsinjurymanager.co.uk/osics.html. Accessed July 3, 2004.

42. Parekh N, Hodges SD, Pollock AM, Kirkwood G. Communicating the risk of injury in schoolboy rugby: using Poisson probability as an alternative presentation of the epidemiology. $\mathrm{Br} \mathrm{J}$ Sports Med. 2012;46:611-613. http://dx.doi. org/10.1136/bjsports-2011-090431

43. Parkkari J, Kujala UM, Kannus P. Is it possible to prevent sports injuries? Review of controlled clinical trials and recommendations for future work. Sports Med. 2001;31:985-995.

44. Pluim BM, Fuller CW, Batt ME, et al. Consensus statement on epidemiological studies of medical conditions in tennis, April 2009. Br J Sports Med. 2009;43:893-897. http://dx.doi. org/10.1136/bjsm.2009.064915

45. Prisk VR, O'Loughlin PF, Kennedy JG. Forefoot injuries in dancers. Clin Sports Med.
2008;27:305-320. http://dx.doi.org/10.1016/j. csm.2007.12.005

46. Quirk R. Ballet injuries: the Australian experience. Clin Sports Med. 1983;2:507-514.

47. Ramel E, Moritz U. Self-reported musculoskeletal pain and discomfort in professional ballet dancers in Sweden. Scand J Rehabil Med. 1994;26:11-16.

48. Russell JA, Shave RM, Yoshioka H, Kruse DW, Koutedakis Y, Wyon MA. Magnetic resonance imaging of the ankle in female ballet dancers en pointe. Acta Radiol. 2010;51:655-661. http:// dx.doi.org/10.3109/02841851.2010.482565

49. Sands WA, Shultz BB, Newman AP. Women's gymnastics injuries. A 5-year study. Am J Sports Med. 1993;21:271-276.

50. Shah S. Caring for the dancer: special considerations for the performer and troupe. Curr Sports Med Rep. 2008;7:128-132. http://dx.doi. org/10.1097/01.CSMR.0000319716.56169.29

51. Solomon R, Micheli LJ, Solomon J, Kelly T. The "cost" of injuries in a professional ballet company: anatomy of a season. Med Probl Perform Art. 1995;10:3-10.

52. Solomon R, Solomon J, Micheli LJ, McGray E. The cost of injuries in a professional ballet com pany: a five-year study. Med Probl Perform Art. 1999;14:164-169.

53. Twitchett E, Angioi M, Koutedakis Y, Wyon M. The demands of a working day among female professional ballet dancers. J Dance Med Sci. 2010;14:127-132.

54. Twitchett $\mathrm{E}$, Angioi M, Koutedakis $\mathrm{Y}$, Wyon $\mathrm{M}$. Video analysis of classical ballet performance. $J$ Dance Med Sci. 2009;13:124-128.
55. van Dijk CN, Lim LS, Poortman A, Strubbe $E H$, Marti RK. Degenerative joint disease in female ballet dancers. Am J Sports Med. 1995;23:295-300.

56. van Mechelen W, Hlobil H, Kemper HC. Incidence, severity, aetiology and prevention of sports injuries. A review of concepts. Sports Med. 1992;14:82-99.

57. Vuillerme N, Forestier N, Nougier V. Attentional demands and postural sway: the effect of the calf muscles fatigue. Med Sci Sports Exerc. 2002;34:1907-1912. http://dx.doi. org/10.1249/01.MSS.0000039062.36895.AB

58. Weatherburn CE. A First Course in Mathematical Statistics. 2nd ed. Cambridge, UK: Cambridge University Press; 1961.

59. Wheeler LP. Common musculoskeletal dance injuries. Chiropr Sports Med. 1987;1:17-23.

60. Wiesler ER, Hunter DM, Martin DF, Curl WW, Hoen $\mathrm{H}$. Ankle flexibility and injury patterns in dancers. Am J Sports Med. 1996;24:754-757.

61. Wikstrom EA, Powers ME, Tillman MD. Dynamic stabilization time after isokinetic and functional fatigue. J Athl Train. 2004;39:247-253.

62. Wyon MA, Abt G, Redding E, Head A, Sharp NC. Oxygen uptake during modern dance class, rehearsal, and performance. J Strength Cond Res. 2004;18:646-649. http://dx.doi. org/10.1519/13082.1

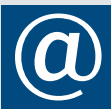

MORE INFORMATION WWW.JOSPT.ORG

\section{BROWSE Collections of Articles on JOSPT's Website}

The Journal's website (www.jospt.org) sorts published articles into more than $\mathbf{5 0}$ distinct clinical collections, which can be used as convenient entry points to clinical content by region of the body, sport, and other categories such as differential diagnosis and exercise or muscle physiology. In each collection, articles are cited in reverse chronological order, with the most recent first.

In addition, JOSPT offers easy online access to special issues and features, including a series on clinical practice guidelines that are linked to the International Classification of Functioning, Disability and Health. Please see "Special Issues \& Features" in the right-hand column of the Journal website's home page. 


\section{[ RESEARCH REPORT ]}

\section{APPENDIX}

Name

Date of birth

Objective examination (continued):

Type of injury: OVERUSE

EXTRINSIC (environmental conditions/equipment/footwear/nutrition/other/other psychological factors/surface/training error)

INTRINSIC (lack of flexibility/LLD/malalignment/muscle imbalance/muscle weakness/other)

Type of injury: TRAUMATIC

EXTRINSIC (collision/accidental contact during partnering/other/props)

INTRINSIC (accelerated/jumping/lunge/other/sidestepping/slip/sudden overload/twist)

Injury grouping

Body part grouping (head-neck/shoulder/arm/wrist-hand/thoracic spine-rib/lumbar spine/pelvis-hip/upper leg/knee/lower leg/ankle/ foot)

Clinical Diagnosis

ORCHARD CODE:

Notes (including investigation/operations):

Contra-indications/precautions:

Complete absence from any dance activities:

Date returned to full activities days 


\section{APPENDIX}

\section{INJURY ASSESSMENT}

Name

Date of birth

Date of injury

Date of assessment

Hours spent exercising that day (between 0 and 10$)$

Intensity (minimum exertion) 1/2/3/4/5/6/7/8/9/10 (maximum exertion)

Hours spent exercising previous day (between 0 and 10 )

Intensity (minimum exertion) 1/2/3/4/5/6/7/8/9/10 (maximum exertion)

Were you hydrated $(\mathrm{V} / \mathrm{N})$ ?

If so, with what (isotonic/water/other)?

How many hours since your last meal (1-12)?

Where did the injury take place (gym/other/stage/pool/studio)?

Activity performed (body conditioning/class/fitness/other/rehab/rehearsal/

weights/performance [show: ])

Movement performed (arabesque/cannot recall/demi-pointe/large jumps/lifted/lifting/middle jumps/nondance related/other/pirouette/plié/pointe/relevé/small jumps)

Footwear worn (ballet/barefoot/jazz/costume/other/pointe/trainers)

Recovery strategy employed (combinations/exercise/ice bath/hydration/meal/none/skins/stretch)

History of present condition:

Occurrence (exacerbation/first episode/recurrence)

Able to continue $(\mathrm{Y} / \mathrm{N})$ ?

If not, reason (forced/precautionary)

Specific side (bilateral/central/left/NA/right)

Specific areas injured

Present stage of healing (acute [3 weeks]/acute on chronic/subacute [3-8 weeks]/chronic [greater than

10 weeks])

Objective examination:
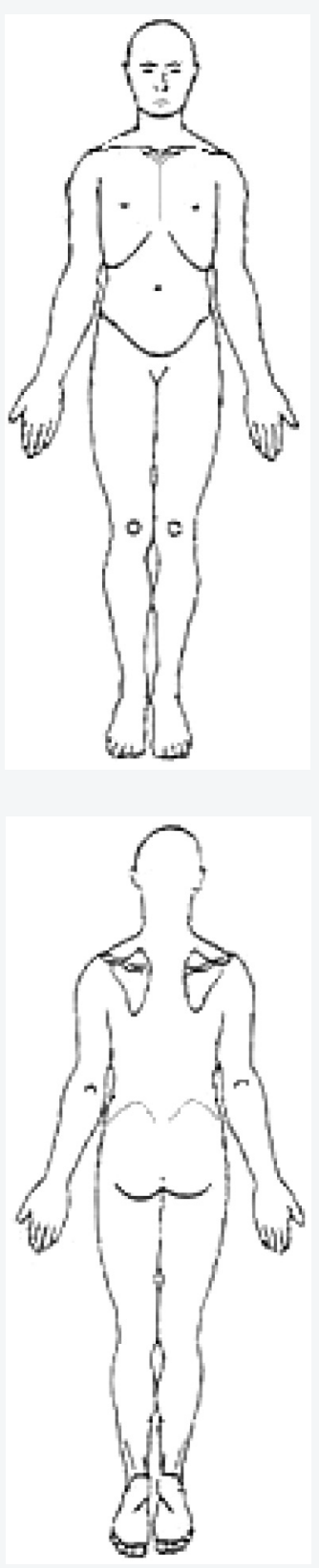